\title{
Experimental analysis of spatter generation and melt-pool behavior during the powder bed laser beam melting process
}

\author{
V. Gunenthiram, P. Peyre*, M. Schneider, M. Dal, F. Coste, I. Koutiri, R. Fabbro \\ PIMM Laboratory, UMR 8006 Arts et Métiers-CNRS-CNAM, 151 Bd de l'Hôpital, 75013 Paris, France
}

Keywords:

Laser

Powder bed

Additive manufacturing

Spatters

Key-hole

\begin{abstract}
A B S T R A C T
The experimental analysis of spatter formation was carried out on an instrumented SLM set-up allowing the quantification of spatter ejections and possible correlation with melt-pool behavior. Considering nearly similar SLM conditions than those carried out on SLM machines, an increase of large spatters ( $>80 \mu \mathrm{m})$ with volume energy density (VED) was clearly demonstrated on a 316L stainless steel, which was attributed to the recoil pressure applied on the melt-pool by the metal vaporization and the resulting high velocity vapor plume. In a second step, much lower spattering was shown on Al-12Si powder beds than on 316L ones. Fast camera analysis of powder beds indicated that droplet formation was mostly initiated in the powder-bed near the melt-pool interface. On Al-12 Si alloys, such droplets were directly incorporated in the MP without being ejected upwards as spatters like on 316L. Last, it was shown that a strong reduction of spattering was possible even on 316L, with the use of low VED combined with larger spots $(\approx 0.5 \mathrm{~mm})$, allowing to melt sufficiently deep layers in conduction regime and ensure adequate dilution between layers.
\end{abstract}

\section{Introduction}

Additive manufacturing (AM) techniques offer appreciable advantages over the conventional subtractive methods. One of them is clearly the complexity of shapes that can be obtained by AM. Among the AM techniques for metals, the selective laser melting (SLM) or laser beam melting (LBM) powder bed process is probably the most attractive technique for building parts with a high degree of complexity as indicated in the pioneer work by Kruth et al. (2004). However, metallurgical defects are still to overcome in SLM parts, including porosities or inclusions. Moreover, the local laser/melt-pool/powder bed interaction is mostly unstable, due the high laser power densities involved or to balling phenomena evidenced at low energy density and investigated in detail by Gu and Shen (2009) and Zhou et al. (2015) respectively on stainless steel or tungsten powders. One of the direct effects of such melt-pool instabilities is the constant generation of liquid spatters, whatever the process conditions considered.

In current SLM machines, such spatters are mostly removed from the powder bed surface by a high velocity shielding gas flow in order to prevent powder bed contamination. However, a significant part of metal ejections either contaminate the powder bed surface or directly fall on the as-built metal, thus promoting metallurgical defects on final parts as indicated by Qiu et al. (2015) on Ti-6Al-4V titanium alloy and Liu et al. (2015) on 316L stainless steel. For such reasons, the characterization of spatter generation and the understanding of underlying physics are of the highest importance to globally improve and stabilize laser melting in powder-bed based ALM processes. Moreover, the formation of residual porosity may be promoted by instability regimes at high energy density and directly or indirectly related to spatter generation.

Several authors like Yadroitsev et al. (2010) have already addressed the melt-pool instabilities in SLM. Most of them have mentioned the formation of a vapor pressure at the top of melt-pool zones for severe power densities but without considering further the possible formation of a recoil pressure and the initiation of a key-hole regime similar to classical deep penetration laser welding conditions. In such a regime, widely investigated by Fabbro (2010), using a sufficiently high energy density to vaporize the metal surface, the laser beam is entrapped in the material volume, through multi-reflections on the walls of a vapor capillary. The resulting effect is an increase of laser absorptivity and bead penetration compared with a heat conduction welding regime. This mostly comes from an in-volume beam absorption compared with a classical surface absorption. However, even on already dense materials, and depending on laser conditions, the key-hole regime can promote specific hydrodynamic instabilities due to interactions between a more or less inclined capillary, the melt-pool, and the surrounding powder bed.

On the one hand Aboulkhair et al. (2016) has already mentioned the

\footnotetext{
* Corresponding author.

E-mail address: patrice.peyre@ensam.eu (P. Peyre).
} 
occurrence of a key-hole formation in SLM powder bed techniques for severe irradiation conditions (high VED values) but without connecting it with process instabilities. On the other hand, recent and highly valuable investigations carried out in Lawrence Livermore Laboratory have widely investigated the hydrodynamic instabilities in SLM. In a preliminary work by King et al. (2014), the threshold for key-hole formation, assumed to be a major contributor to the formation of defects, was calculated by considering the depth variation versus a normalized enthalpy value. The experimental and numerical work detailed in Matthews et al. (2016) focused on the denudation phenomena occurring near SLM beads and concluded that inward lateral gas flow induced by the melt-pool vaporization was the main dragging force for powder depletion. Khairallah et al. (2016) also considered key-hole closure as a possible explanation for porosity formation, and confirmed that melt-pool vaporization was a key factor for the formation of spatters and denudation.

Wang et al. (2017) has considered three main types of spatter ejections (droplet spatters coming from the melt-pool surface instability, spatters included in the metallic jet and coming from the recoil pressure zone, and non-melted powder spatters at the front of the melt-pool). The key-hole formation is clearly mentioned as a contributor to spattering, but no quantification of spatters versus process parameters was shown. Attempts for quantifying spatters have been proposed by Ozel et al. (2016) using a high speed thermal camera on Inconel 625 alloy. Authors evidenced a $30-40 \%$ ratio between spatters emissive surface and global melt surface (melt-pool + spatters) but without a precise focus on spatters shape and frequency.

In Gunenthiram et al. (2016), instability regimes in SLM were also evidenced either in the form of balling or humping issues. The first one (Balling) has been widely reported to be due to a lack of melting of the substrate and resulting spheroïdisation effects whereas humping (periodic formation of humps and valleys) was attributed to large (length/ width) melt pool ratios generating Plateau - Rayleigh instabilities. However, a possible correlation between MP instabilities and spatter formation was not fully addressed.

Masmoudi et al. (2015) also investigated the influence of surrounding atmosphere on the stability and shape of SLM melt-pools. They carried out a simplified modeling of vapor plume expansion at ambient and low pressure, and indicated that working under work pressure (like EBM) was not beneficial for the stability of SLM beads, due to excessive vaporization effects.

In most of the pre-mentioned works, many authors have considered a volume energy density (VED) as a main design parameter for SLM. However Scipioni Bertoli et al. (2017) mentioned that such a parameter is not fully sufficient to predict the stable SLM regimes, due to the complex physics involved either at low VED or at high VED values.

Considering specifically the Simonelli et al. (2015) on 316L, Al$10 \mathrm{Si}-\mathrm{Mg}$ and Ti-6Al-4V where authors mostly focused on the postmortem analysis of large collected spatters $(100-300 \mu \mathrm{m})$ widely enriched with $\mathrm{O}_{2}$ and volatile elements during their melting + solidification time.

Various thermo-hydraulic simulations approaches have been attempted, either for the calculation of SLM melt-pools (Khairallah and Anderson, 2014), or for the calculation of welding melt-pools and associated instabilities (Wu et al., 2017). However, they are not considered as fully predictive yet. They only can provide useful data on instability formations and interesting insight on the underlying physics.
Following all these works, the objective of the present study was to investigate and quantify the formation of spatters during SLM, and to address the possible influence of a melt-pool behavior and/or key-hole formation on such instabilities. The use of a VED parameter was also considered to compare the different experimental conditions.

For this purpose, single SLM beads were carried out on an instrumented SLM set-up using incremental SLM conditions and a unique single powder bed thickness of $70 \mu \mathrm{m}$ considering a AISI 316L stainless steel, and a 4047 (Al-12Si) Aluminum alloy powder.

One concern is how a single beads approach may be representative of a full SLM process, where heat accumulation with additive layers is supposed to enlarge melt pools and increase maximum temperatures. Investigations on single beads have been previously carried out by many authors such as Yadroitsev et al. (2010), King et al. (2014), Khairallah et al. (2016) and Matthews et al. (2016), for investigating the physics of SLM. In the following work, single beads are considered to be representative of the first stage of a SLM process, near the platform, where the average temperature has not reached a high and stabilized level yet.

\section{Experimental conditions}

\subsection{Materials}

Two powder materials were used: a 316L stainless steel powder (Fe - $17.1 \mathrm{Cr}-11.9 \mathrm{Ni}-2 \mathrm{Mo}$ ) with a $15-45 \mu \mathrm{m}$ powder diameter $\left(D_{50} \approx 25 \mu \mathrm{m}\right)$, and a 4047 aluminum-silicon alloy powder ( $\mathrm{Al}-12 \mathrm{Si}$ ) with nearly the same grain distribution. Such powder distributions were analyzed using a laser-based particle size analyzer operating in liquid phase. SEM investigations also confirmed that powder grains were for both materials mostly spherical, due to the gas atomization process. Prior to powder spreading, powders were dried at least during $24 \mathrm{~h}$ at $60-70{ }^{\circ} \mathrm{C}$ to remove adsorbed water susceptible to modify the melt-pool behavior.

$1 \mathrm{~mm}$-thick sheets (316L steel or AA6016 (AlMgSi) alloy) were also used as starting substrates to spread powder layers. Thermo-physical properties of powders mostly taken in Mills (2002) are summarized in Table 1.

The main difference is that $\mathrm{Al}$ alloy exhibits a 4 times lower heat diffusivity $\left(\mathrm{a}=\lambda / \mathrm{\rho C}_{\mathrm{p}}\right)$ than $316 \mathrm{~L}$ steel in near-fusion state, combined with a higher vaporization enthalpy. Moreover, the absorptivity of laser wavelength is expected to be two times lower on $\mathrm{Al}$ alloys.

\subsection{Generation of single tracks by selective laser melting (SLM)}

Taking into consideration that there is a limited free volume and access to diagnostic implementation in SLM machines, simple powder bed laser melting experiments were carried out on a dedicated and simplified set-up, allowing much easier analysis of the powder bed melting phenomena, and specifically of the spatter ejections. Using high speed camera with different collection angles, our objectives were mostly to visualize the localization of spatter generation and to quantify the amount, the size and the nature of spatters for a large range of experimental conditions (various laser power $P_{0}$ and scan speed $V_{0}$ ), a constant laser beam diameter $(200 \mu \mathrm{m}$, top-hat), and a single and constant powder bed layer height $(70 \mu \mathrm{m})$ deposited on a metal substrate using a razor edge (Fig. 1). A Yb:YAG laser operating at $1030 \mathrm{~nm}$

Table 1

Thermo-physical properties of 316L steel and A4047 Al alloy at the liquid state (Mills, 2002).

\begin{tabular}{|c|c|c|c|c|c|c|c|c|c|}
\hline Alloy & pa $\left(\mathrm{kg} / \mathrm{m}^{3}\right)$ & $\mathrm{T}_{\mathrm{m}}(\mathrm{K})$ & $\mathrm{T}_{\text {vap }}(\mathrm{K})$ & $\left.\lambda^{\mathrm{a}} \mathrm{(W} / \mathrm{m} \mathrm{K}\right)$ & $\mathrm{C}_{\mathrm{p}}^{\mathrm{a}}(\mathrm{J} / \mathrm{Kg} \mathrm{K})$ & aa $\left(\mathrm{mm}^{2} / \mathrm{s}\right)$ & $\Delta \mathrm{H}_{\text {vap }}(\mathrm{kJ} / \mathrm{kg})$ & $\eta(\mathrm{Pa} \mathrm{s})$ & $\sigma(\mathrm{N} / \mathrm{m})$ \\
\hline $316 \mathrm{~L}$ & 7100 & 1700 & 2850 & 28 & 750 & 5.3 & 6300 & 0.007 & 1.7 \\
\hline A4047 & 2550 & 845 & 2700 & 68 & 1150 & 23 & 10900 & 0.0012 & 0.9 \\
\hline
\end{tabular}

${ }^{\mathrm{a}}$ At the melting point. 
(a)

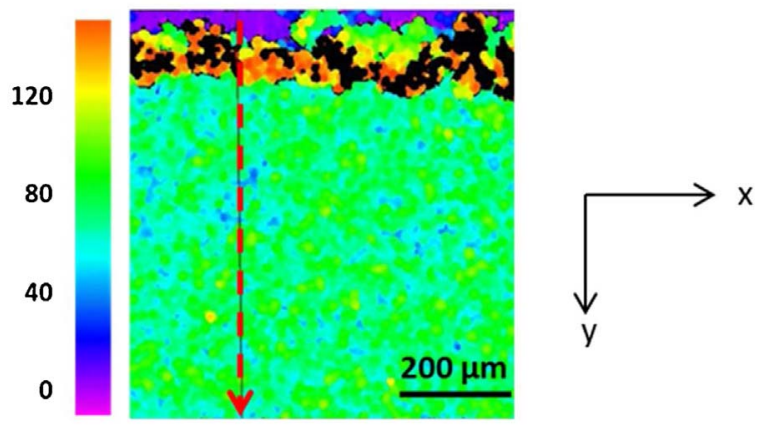

(b)

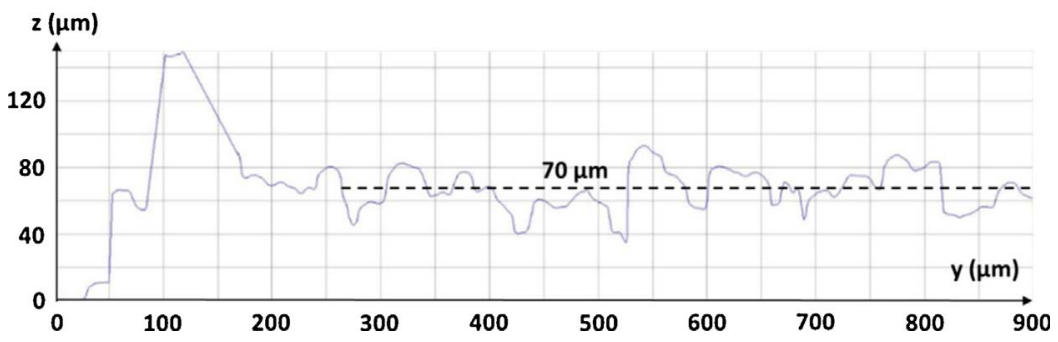

was used with output laser powers between $100 \mathrm{~W}$ and $1500 \mathrm{~W}$, and the samples were moved versus the laser using a high-speed $(\mathrm{O}, \mathrm{x})$ table at scan velocities V up to $0.75 \mathrm{~m} / \mathrm{s}$. Such conditions were considered to be realistic compared with a real SLM process. The main difference to mention is the gas shielding: in our case, only a local $0.1 \mathrm{~m} / \mathrm{s}$ Argon shielding was used through a $15 \mathrm{~mm}$ diameter nozzle (similar to a welding procedure) whereas SLM parts are built in a global Ar chamber. The resulting $\mathrm{O}_{2}$ content (estimated with an $\mathrm{O}_{2}$ probe) was shown to be near $0.1 \%(\approx 1000 \mathrm{ppm})$ using a gas nozzle to be compared with less than $500 \mathrm{ppm}$ in a SLM chamber. In both cases, SLM beads were found to be shiny and apparently not oxidized but the difference in $\mathrm{O}_{2}$ content could have provoked tiny modifications of the melt-pool Marangoni flow. Another difference with usual laser irradiation in SLM machines is the spatial distribution of the laser beam which is uniform in the present work, and monomode-Gaussian in most of the industrial SLM setups without beam shaping.

SA2 Photron - Fastcam high speed camera were used to investigate melt-pools and spatter ejections, with the use of two collection angles: $0^{\circ}$ and $60^{\circ}$ (Fig. 2). The analysis of spatter ejection was carried out with a $0^{\circ}$ angle and a frequency rate of $4000 \mathrm{fr} / \mathrm{s}$ whereas a $12500 \mathrm{fr} / \mathrm{s}$ frequency rate was used for the analysis of melt-pool and spatter formation at $60^{\circ}$ angle (Fig. 2). For this latter experiment, a pulsed laser diode $(\lambda=0.83 \mu \mathrm{m})$, synchronized with the fast camera acquisition rate was used to illuminate powder melting scenes and improve their contrast. Following video capture, an image analysis freeware (ImageJ) was used with a two-step procedure: (1) generation of a binary file using a constant brightness threshold, (2) analysis of spatters (numbers, size, surface ratio). For each video of spatter generation captured at $4000 \mathrm{fr} / \mathrm{s}, 200$ images were analyzed automatically and the data were collected and treated by a simple excel routine.

Only single SLM beads, considered to be representative of the whole SLM process, were carried out using process conditions presented in Table 2. For each condition, two or three tests were carried out to provide statistically reliable data. A volume energy density (VED: Eq. (1)) was calculated for each experimental condition $\left(P, V_{s}\right)$, in order to correlate possible changes of fusion regimes with a reliable energetic parameter. Process conditions presented in Table 2 have been chosen because they provide similar VED range $\left(20-200 \mathrm{~J} / \mathrm{mm}^{3}\right)$, and resulting bead penetration than classically used on most of the SLM machines. To provide similar VED values than previous works (Scipioni Bertoli et al., 2017), we have increased laser power accordingly (up to $2 \mathrm{~kW}$ ).

It has to be mentioned that previous investigations have also considered different formulations of VED, including for instance the powder layer thickness $\Delta \mathrm{h}$ like in Khairallah et al. (2016) or the hatch distance $h$. In our case, only parameters related to the laser irradiation $\left(\mathrm{P}, \mathrm{V}_{\mathrm{s}}, \mathrm{D}\right)$ were considered.

$\mathrm{VED}=\frac{4 \mathrm{P}}{\pi \cdot \mathrm{D}^{2} \cdot \mathrm{V}_{\mathrm{S}}}$

With VED $=$ Volume Energy density $\left(\mathrm{J} / \mathrm{mm}^{3}\right), P=$ laser power $(\mathrm{W})$, $\mathrm{V}_{\mathrm{s}}=$ scan speed $(\mathrm{mm} / \mathrm{s}), \mathrm{D}=$ laser spot diameter $(\mathrm{mm})$.

\section{Analysis of spatters formed on a 316L steel powder bed}

\subsection{Generation of spatters}

According to the videos recorded with a $60^{\circ}$ angle, most of the spatters are initiated at the interface between the powder bed and the front part of the melt-pool, i.e on a semi-half circle surrounding the melt-pool front (Fig. 3a and b). This corresponds to a thin melt-pool zone comprised between the central and depressed part clearly shown on the videos and the powder bed. This depressed part is attributed to the vertical vapor pressure $\mathrm{P}_{\text {vap }}$ applied downwards on the melt-pool surface due to an intensive vaporization at elevated power density. Such a pressure can be roughly estimated using the Clapeyron's equation. The melt-pool surface deformation clearly reveals at least the initiation or the full formation of a key-hole regime which affects the hydrodynamic behavior of a SLM melt-pool already addressed by Gunenthiram et al. (2016). In turn, comparisons can be made with the key-hole/melt-pool interactions in laser welding widely investigated by Fabbro (2010).

The mechanisms for droplet generation and ejection (Figs. 3 and 4) can be summarized as follows: (1) due to conduction heating of the surrounding powder bed, powder grains in close contact with the upper and lateral side of melt-pool tend to agglomerate to form larger liquid droplets, (2) For low VED values, such droplets are incorporated to the MP whereas above a VED threshold generating more or less intense vaporization, a possible key-hole regime and accelerated liquid flow backwards, such droplets are accelerated sheared upwards by the 
(a)

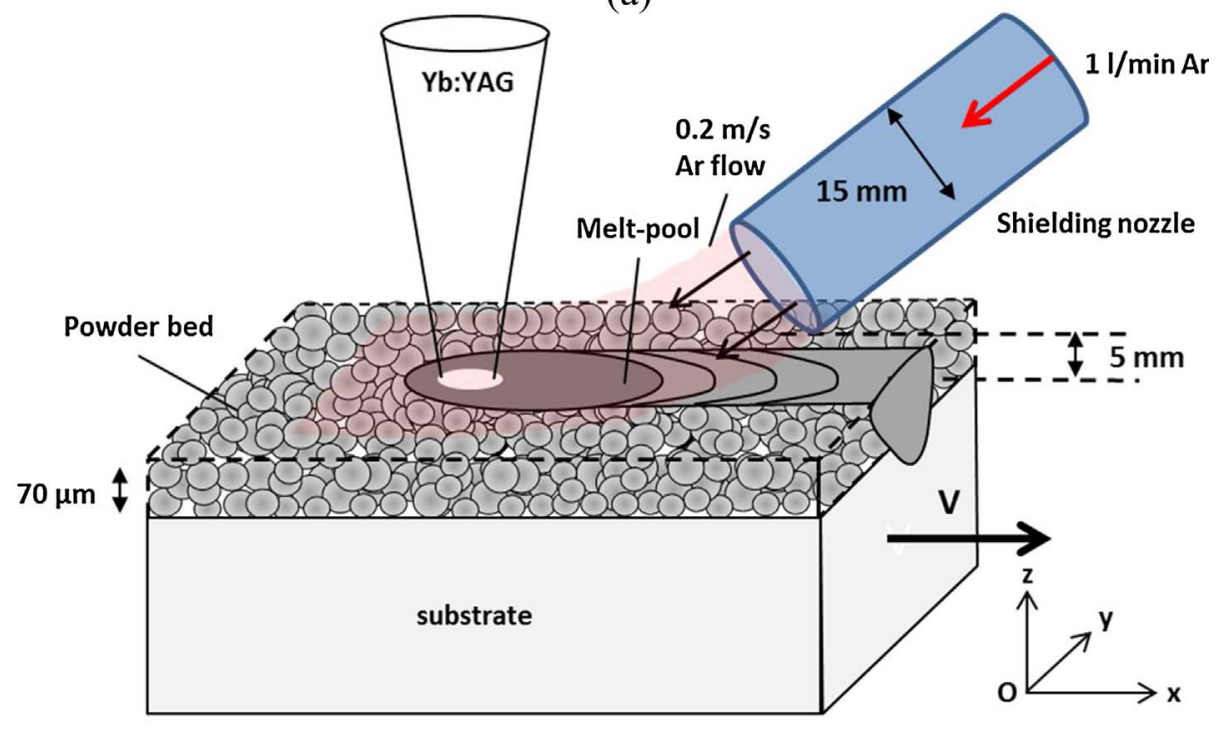

(b)

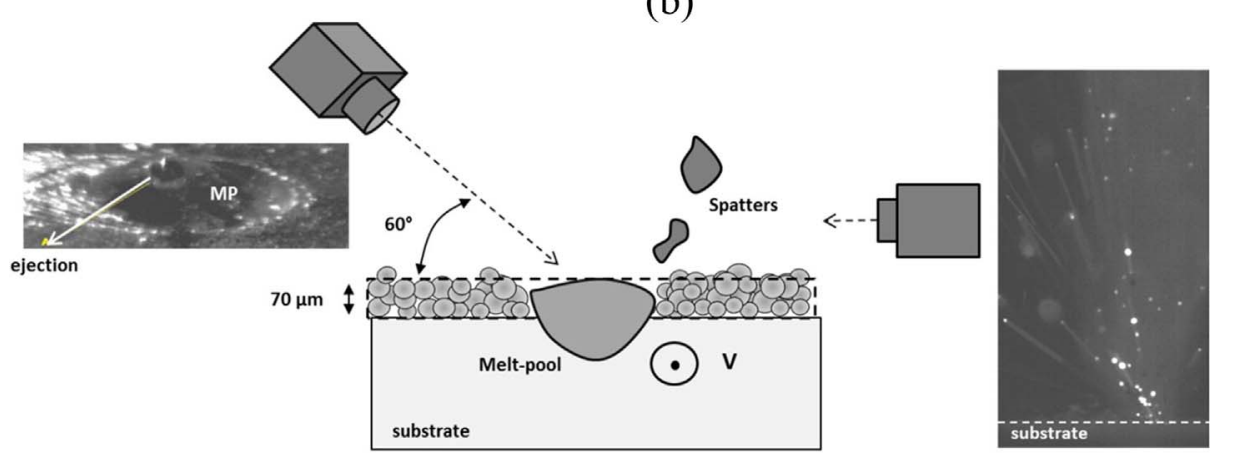

Fig. 2. Simplified scheme of the powder bed laser fusion using a local gas shielding and a $(\mathrm{O}, \mathrm{x})$ table: (a) side view, (b) front view with a lateral $\left(0^{\circ}\right)$ and $60^{\circ}$ inclined fast camera analysis of laser-melt-poolpowder bed interactions (the laser scans perpendicularly to the figure).
Table 2

Experimental conditions for single SLM beads on 316L and 4047 powder beds (laser diameter $=200 \mu \mathrm{m}$ ) and geometry of beads ( $*$ test with $\mathrm{D}=500 \mu \mathrm{m}$ ).

\begin{tabular}{|c|c|c|c|c|c|c|c|}
\hline Reference & $\mathrm{P}(\mathrm{W})$ & Vs $(\mathrm{m} / \mathrm{s})$ & $\begin{array}{l}\text { VED } \\
(\mathrm{J} / \\
\left.\mathrm{mm}^{3}\right)\end{array}$ & $\begin{array}{l}\text { Depth d } \\
316 \mathrm{~L} \\
(\mu \mathrm{m})\end{array}$ & $\begin{array}{l}\text { Width } \\
\text { w 316L } \\
(\mu \mathrm{m})\end{array}$ & $\begin{array}{l}\text { Depth d } \\
4047 \\
(\mu \mathrm{m})\end{array}$ & $\begin{array}{l}\text { Width } \mathrm{w} \\
4047 \\
(\mu \mathrm{m})\end{array}$ \\
\hline P220V033 & 220 & 0.33 & 21.2 & 0 & 225 & - & - \\
\hline P320V033 & 320 & 0.33 & 30.9 & 40 & 235 & 85 & 330 \\
\hline P520V033 & 520 & 0.33 & 49.9 & 135 & 300 & 120 & 380 \\
\hline P720V033 & 720 & 0.33 & 69.4 & 230 & 339 & 163 & 435 \\
\hline P1120V033 & 1120 & 0.33 & 108.0 & 365 & 429 & 472 & 581 \\
\hline P1520V033 & 1520 & 0.33 & 146.6 & 489 & 456 & 545 & 738 \\
\hline P1920V033 & 1920 & 0.33 & 185.2 & - & - & 709 & 890 \\
\hline P220V054 & 220 & 0.54 & 13.5 & 0 & 144 & - & - \\
\hline P320V054 & 320 & 0.54 & 19.6 & 32 & 205 & - & - \\
\hline P720V054 & 720 & 0.54 & 44.1 & 105 & 203 & - & - \\
\hline P1120V054 & 1120 & 0.54 & 68.6 & 197 & 218 & - & - \\
\hline P1520V054 & 1520 & 0.54 & 93.0 & 289 & 238 & 305 & 454 \\
\hline P1920V054 & 1920 & 0.54 & 117.5 & - & - & 422 & 513 \\
\hline P2320V054 & 2320 & 0.54 & 141.9 & - & - & 573 & 727 \\
\hline P220V075 & 220 & 0.75 & 9.3 & 0 & 168 & - & - \\
\hline P320V075 & 320 & 0.75 & 13.6 & 15 & 187 & - & - \\
\hline P720V075 & 720 & 0.75 & 30.6 & 75 & 175 & 86 & 321 \\
\hline P1120V075 & 1120 & 0.75 & 47.5 & 135 & 210 & - & - \\
\hline P1520V075 & 1520 & 0.75 & 64.5 & 195 & 205 & 227 & 350 \\
\hline P1920V075 & 1920 & 0.75 & 81.5 & - & - & 327 & 431 \\
\hline P2320V075 & 2320 & 0.75 & 98.4 & - & - & 391 & 435 \\
\hline P720V033* & 720 & 0.33 & 11.1 & - & - & 220 & 500 \\
\hline
\end{tabular}

metallic gas plume and ejected. The mechanisms for lateral attraction of liquid droplets or solid grains to the melt-pool by Bernoulli-like effects are detailed by Matthews et al. (2016).

An interesting point to notice is that spatters are also widely generated in the balling regime (low VED) where the melt-pool spheroïdizes under the action of surface tensions due to a lack of dilution with the substrate. As a comparison, laser beam "bead on plate" melting tests carried out with the same $(\mathrm{P}, \mathrm{V})$ experimental conditions, but without powder, did not generate spatters, or to a limited extent. Such result confirms the influence of boundary conditions: spatters generation come from the combination of high VED $\left(>10 \mathrm{~J} / \mathrm{mm}^{3}\right)$ laser interaction with a melt-pool surrounded by a powder bed.

\subsection{Influence of laser power and scan speed on spatter generation}

The evolution of spatter size and number with laser power and scan speed was analyzed with a $0^{\circ}$ angle allowing a better contrast between particles and surrounding atmosphere (Figs. 5-7).

Such videos not only show the ejection of bright molten droplets, but also the occurrence of a vapor plume. Most of the ejected liquid droplets are comprised between $20 \mu \mathrm{m}$ and $200 \mu \mathrm{m}$ in diameter, i.e much larger than the particles constituting the powder bed. A limited number of ejections can also overpass $200 \mu \mathrm{m}$.

The velocity of spatters, calculated by considering spatter positions between two consecutive frames (i.e $0.25 \mathrm{~ms}$ at $4000 \mathrm{~Hz}$ ), was shown to vary between $3+/-1.5 \mathrm{~m} / \mathrm{s}$ (for most of the "large" spatters) and $35+/-15 \mathrm{~m} / \mathrm{s}$ (for the smaller ones of less than $20 \mu \mathrm{m}$ in diameter). This result is shown in Fig. 5 for three distinct (P, V) experimental conditions. It indicates two distinct mechanisms for spatter ejection: 


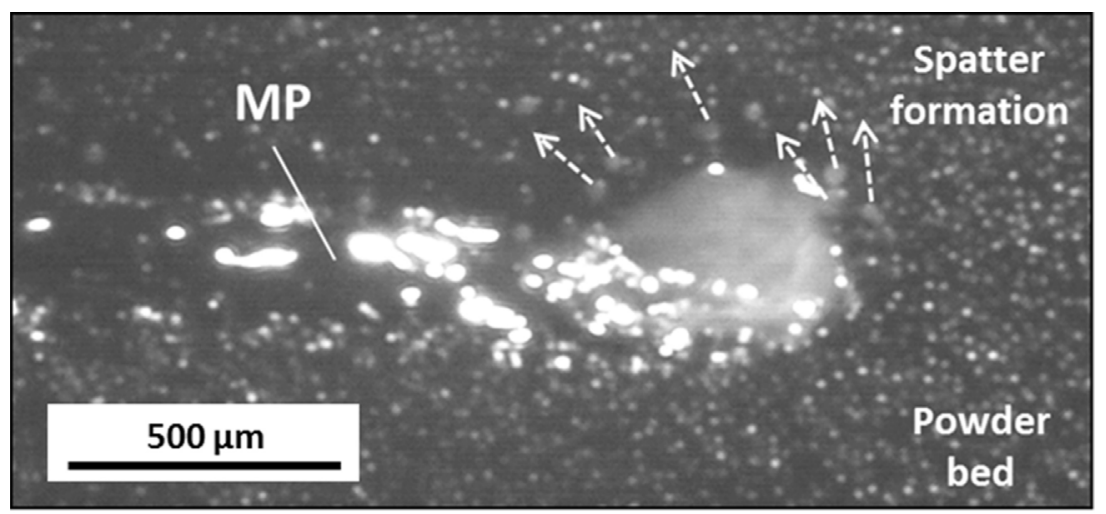

Fig. 3. High speed camera analysis of a 316L melt-pool with a $60^{\circ}$ angle. (a) $\mathrm{V}=0.33 \mathrm{~m} / \mathrm{s}, 1520 \mathrm{~W}$ : Spatters are initiated at the front edge of the melt-pool, near the powder bed/MP interface, (b) $\mathrm{V}=0.75 \mathrm{~m} / \mathrm{s}, \mathrm{P}=1520 \mathrm{~W}$ in humping regime, MP is more unstable but the amount of spatters is not increased.

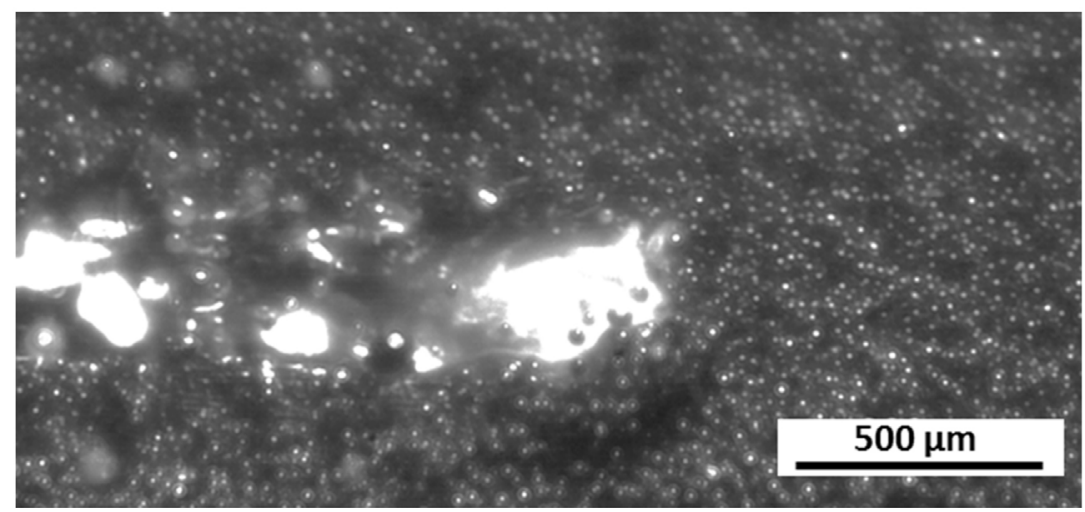

tiny powder bed grains near the melt-pool are entrained by the gas plume velocity whereas a significant amount of kinetic energy is transferred to large spatters.

Globally, an increase of laser power globally increases the number of ejected spatters. Moreover, the ratio of large ejected melt-pool particles $(>70 \mu \mathrm{m})$ is increased with higher powers, which may enhance the contamination of the powder bed surface (Figs. 6 and 7). Similarly, a decrease of scan speed tends to increase the number of spatters, except for the P1520V033 condition (VED $\approx 148 \mathrm{~J} / \mathrm{mm}^{3}$ ) which exhibits lower spattering.

\section{Analysis of spatters during SLM single tracks on A4047 aluminum powder bed}

Different tests were also carried out with a 4047 Aluminum wrought alloy and the same $70 \mu \mathrm{m}$-thick powder bed to evaluate the influence of powder material on spatter ejection, and compare melt-pool behavior. By superimposing 1000 video images, it can be clearly seen that ejections are lowered on A4047, whatever the process conditions (Fig. 8). Moreover, for both materials, the range of ejections angles was shown to increase and to become more vertical with laser power.

Quantitatively, ejections are nearly 3 times lower on 4047 Aluminum powder than on $316 \mathrm{~L}$ steel for similar $\left(\mathrm{P}, \mathrm{V}_{\mathrm{s}}\right)$ process
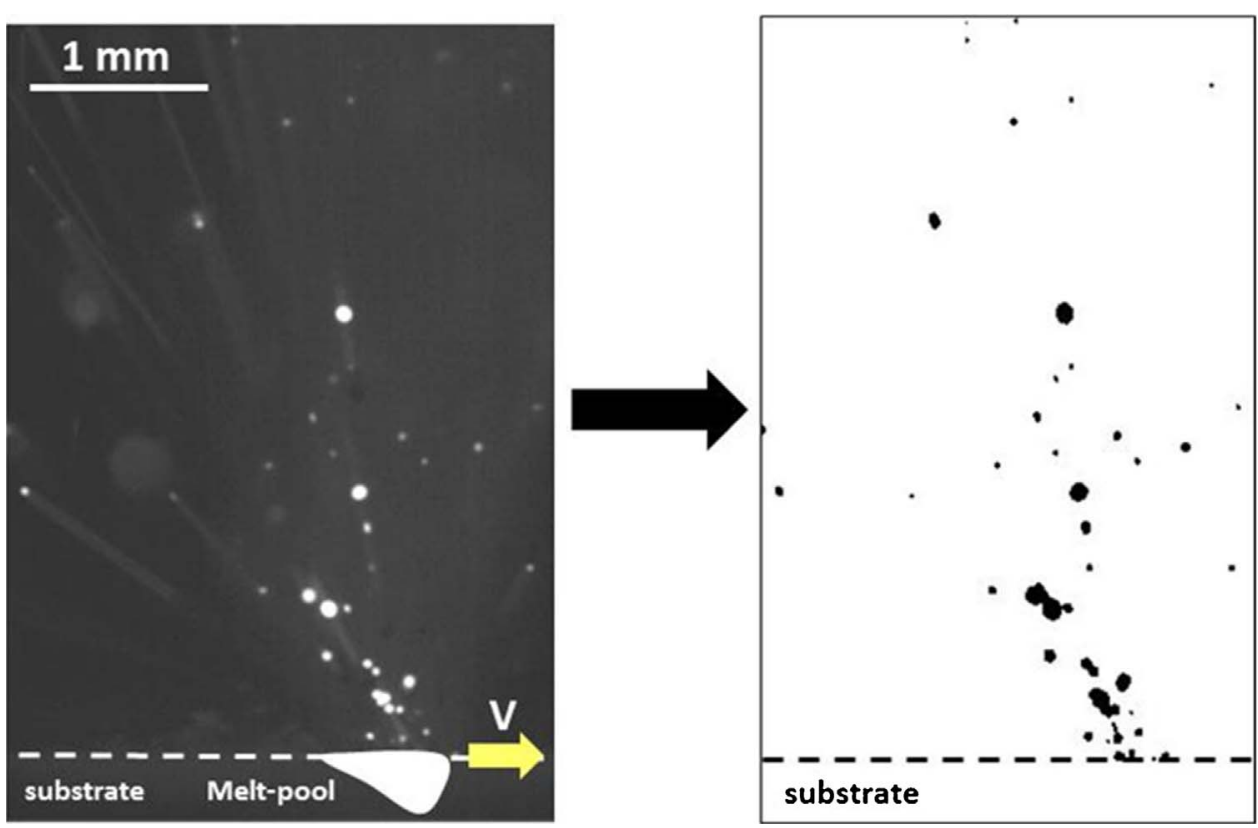

Fig. 4. Definition of a brightness threshold and generation of a binary file from a video of spatter generation $\left(0^{\circ}\right.$ angle). 


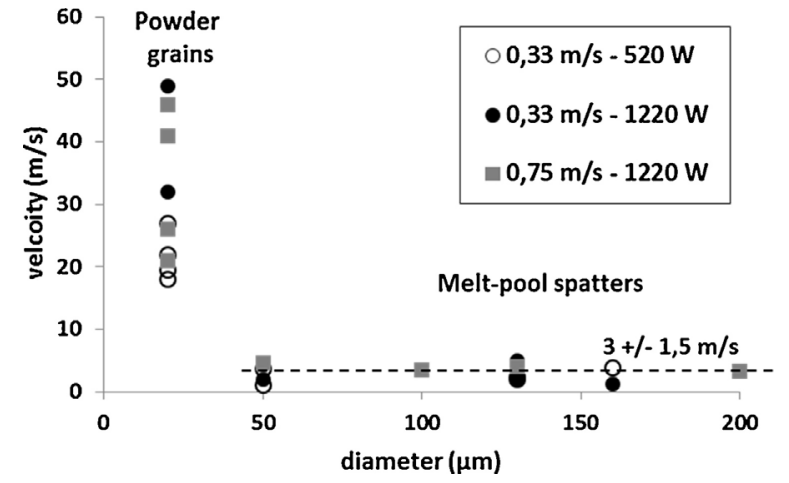

Fig. 5. velocity of ejected particles versus particle diameter on $316 \mathrm{~L}$ steel. A difference is shown between relatively large melt-pool spatters ejected at $3+/-1.5 \mathrm{~m} / \mathrm{s}$ and small powder grains $(\approx 20 \mu \mathrm{m}$ in diameter) ejected at 10 times higher velocity $(35+/-15 \mathrm{~m}$ / s).

condition (Fig. 9). Similar results were also obtained on A5086 (Al$4.5 \mathrm{Mg}$ ) Al alloy. Additionally, spatter velocities are in the same order of magnitude than on $316 \mathrm{~L}$ steel.

Results indicate (Fig. 10) for both materials that spatter generation increases with volumetric energy density VED, except for the experimental conditions (lowVED) pvoking balling. The difference in spatter amount is also really clear between aluminum and steel. On the other hand, no real correlation was evidenced between the occurrence of humping instabilities and spatter ejection (Fig. 7).

To understand this difference of behavior between $\mathrm{Al}$ and steel, several factors can be considered: (1) due to solid $\mathrm{Al}_{2} \mathrm{O}_{3}$ oxides floating on Aluminum melt-pools, liquid flow is reduced compared with other metals. This phenomenon partly explains why densification is hard to achieve with SLM on $\mathrm{Al}$ alloys, (2) the liquid volume is strongly reduced on $\mathrm{Al}$ alloys due to higher reflectivity, and to an increase of keyhole formation threshold. On the other hand, according to (Mills, 2002) surface tensions are two times lower on $\mathrm{Al}$ alloys than on 316L steel (Table 1). This last property should favor MP instability on Al alloys, which is not practically true, but should also promote easier spheroïdisation on steel, with higher heat concentration. Last-but not leastthe vaporization enthalpy of aluminum-silicon alloys is much higher than on 316L (Table 1), which could promote lower vaporization rate.

\section{Analysis of melt-pool shapes and affected depths}

The analysis of melt-pool shapes (width w, penetration depth d) is of

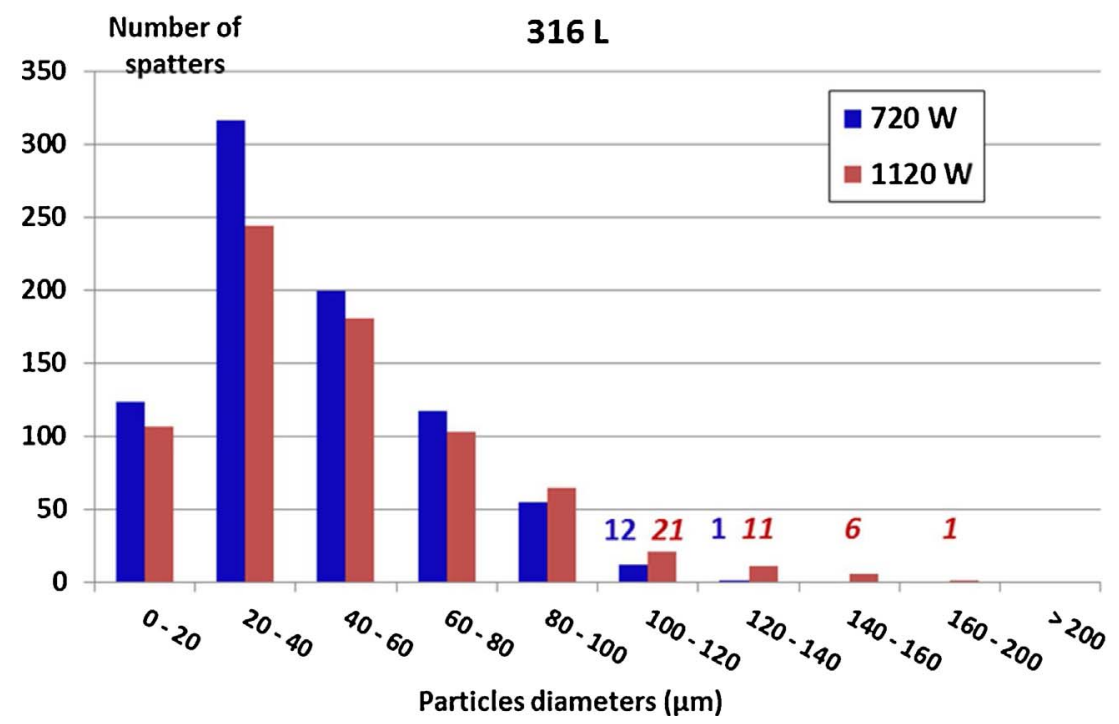

high importance to understand the physics of selective laser melting and more widely of laser welding.

Cross-sections were carried out to estimate bead morphologies on both 316L and A4047. The transition from a stable regime (low VED) to a "humped" regime is clearly shown on steel and aluminum (Figs. 11 and 12). Above a given VED value, and a resulting d/D ratio, a key-hole mode is assumed to be the main contributor to laser absorption. Results indicate that the presence of the powder bed layer (systematically lower than $100 \mu \mathrm{m}$ ) does not play a dominant role in the formation of the welding regime. Another interesting point to notice is that, for a constant laser spot diameter, the affected depth tends to follow a linear dependence versus VED (Fig. 13). Such a linear dependence is not affected by the powder nature (steel or aluminum), and by the presence of the powder bed: similar results (approximately shifted of $\mathrm{a}-\Delta \mathrm{h} / 2$ value) are shown on bead-on-plate results.

Due to a 4 times higher thermal diffusivity of A4047, MP widths are shown to be strongly increased (Table 2) and melt-pool lengths strongly reduced compared with 316L resulting in smaller (length/width) ratios. This results in a lower humping tendency because such Rayleigh-Plateau like instabilities, obtained in Gunenthiram et al. (2016) for high velocity, high power conditions, are observed for length over width ratio $>>\pi$. This is confirmed on cross-sections where undercuts and humping are visible only above $1520 \mathrm{~W}$ (Fig. 12).

The occurrence or not of a key-hole regime depends on the criterion considered for key-hole initiation or stable formation. According to Khairallah et al. (2016) one can consider a key-hole regime when d/ $\mathrm{D}>1$, i.e when the inclination angle of the key-hole front wall exceeds $45^{\circ}$. This corresponds to a VED $=65 \mathrm{~J} / \mathrm{mm}^{3}$ threshold value (Fig. 10).

Considering the same approach than (Hann et al., 2011), already used by Scipioni Bertoli et al. (2017). for SLM, we also tried to correlate normalized bead penetrations (e/D) for both materials with a normalized enthalpy value $\Delta H / h_{s}$ incorporating the thermo-physical properties of irradiated materials (diffusivity $\alpha$ ). In a logarithmic scale, and considering recent reflectivity data obtained in Gunenthiram et al. (2016), bead penetrations obtained on 316L and A4047 can be rather correctly represented on a single curve (Fig. 14).

$\frac{\Delta \mathrm{H}}{\mathrm{h}_{\mathrm{s}}}=\frac{\mathrm{A} \cdot \mathrm{P}}{\mathrm{h}_{\mathrm{s}} \pi \sqrt{\mathrm{D}^{3} \alpha \mathrm{V}_{\mathrm{s}}}}$

With $h_{s}\left(J / m^{3}\right)=$ volume enthalpy at melting $=\rho \cdot C_{p} \cdot\left(T_{m}-T_{0}\right), \alpha$ $\left(\mathrm{m}^{2} / \mathrm{s}\right)=$ thermal diffusivity, $\mathrm{A}=$ absorptivity (around 0.4 for $316 \mathrm{~L}$ and 0.2 for A4047).

Fig. 6. Influence of process conditions on spatters generation $(\mathrm{V}=0.33 \mathrm{~m} / \mathrm{s})$. The increase from $720 \mathrm{~W}$ to $1220 \mathrm{~W}$ provokes a factor 2 to 3 increase of large spatters $(>80 \mu \mathrm{m})$ (316L steel). 


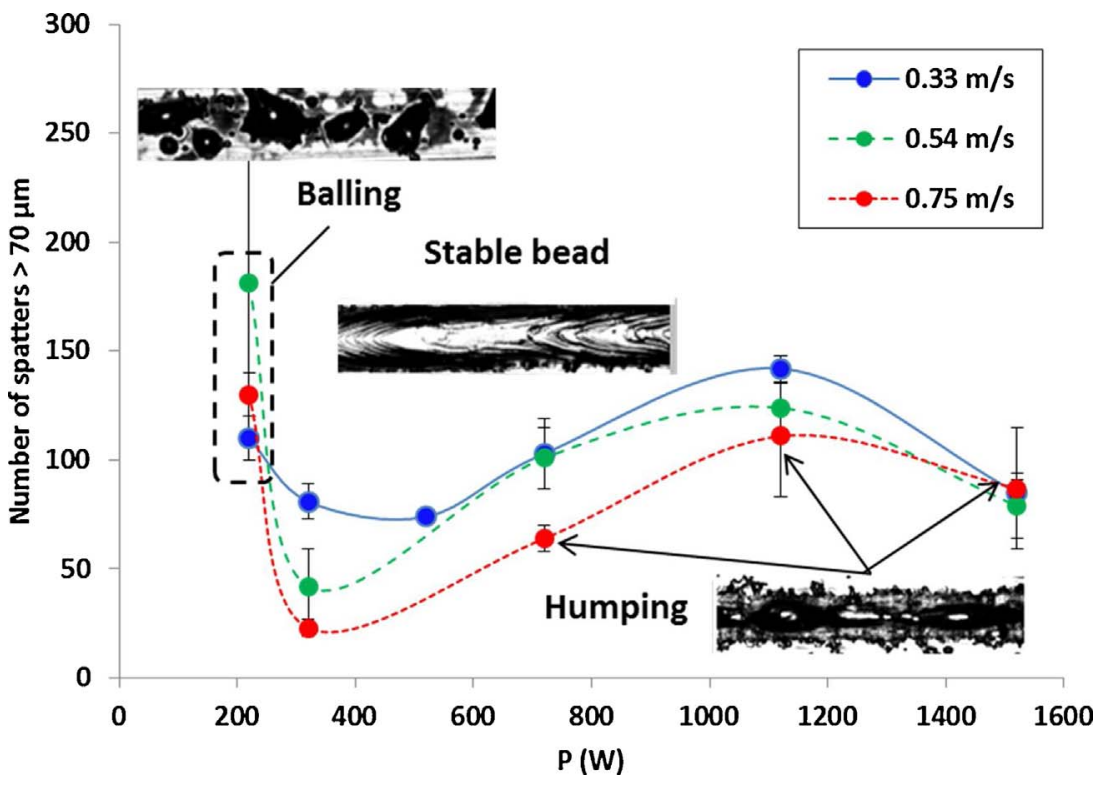

Fig. 7. Influence of laser power and scan speed on the generation of large $(\mathrm{D}>70 \mu \mathrm{m})$ spatters on a $316 \mathrm{~L}$ powder bed. For low laser powers $(\mathrm{P}=220 \mathrm{~W})$ and resulting VED values severe balling occurs, that generates important spattering. The lower amount of spatters is obtained for $\mathrm{P}$ values just above the balling threshold $(\mathrm{P}=320 \mathrm{~W}$, $\mathrm{V}=0.54 \mathrm{~m} / \mathrm{s}$ and $0.75 \mathrm{~m} / \mathrm{s}$ ).

\section{Discussion}

\subsection{Summary}

Experimental results have been presented in this paper concerning spatter formation, including experimental data on spatter size and velocity for two distinct metals: a 316L stainless steel and A4047 wrought aluminum alloy. They confirm the occurrence of large spatters $(>0.1 \mathrm{~mm})$ that can contaminate powder bed surfaces and generate inclusions in solidified parts. These results also confirm the overall influence of vaporization phenomena already mentioned by all the recent works carried out in Livermore Lab. (King et al., 2014; Matthews et al., 2016).

In a recent work of Wang et al. (2017) different origins are assumed for spatter formation, including melt-pool fluid flow (Marangoni) as a possible mechanism for ejection, directly from the melt-pool volume (called type II spattering). In the present work, and for our experimental conditions, such a mechanism was not identified with the use of fast cameras, even in a very severe (high VED) humping-like condition. Most of our results indicate that spatters are formed in the powder bed near the melt-pool, attracted to the melt-pool surface by Bernoulli-like effects (Matthews et al., 2016), and ejected upwards (mode III spatters identified by Wang et al. (2017)). However, the type of powder (CoCr alloy in Wang et al. (2017)) may explain why on 316L and 4047, we did not evidence type II spattering, due to specific thermo-physical properties (viscosity and surface tensions) in CoCr melt-pools.

During laser-melt-pool interaction and above a given VED value ( $\approx 65 \mathrm{~J} / \mathrm{mm}^{3}$ on $316 \mathrm{~L}$ steel) a key-hole can form (Fig. 13), resulting from the vapor pressure applied on the MP and entrapping laser energy. In this regime, the melt-pool front part is shrunk between the vapor capillary and the surrounding powder bed. This results in a backwards fluid acceleration of the confined liquid provoking what Khairallah et al. (2016) call a "bow wave" which upper surface is mostly positioned above the initial powder bed surface. In SLM, the spatters are

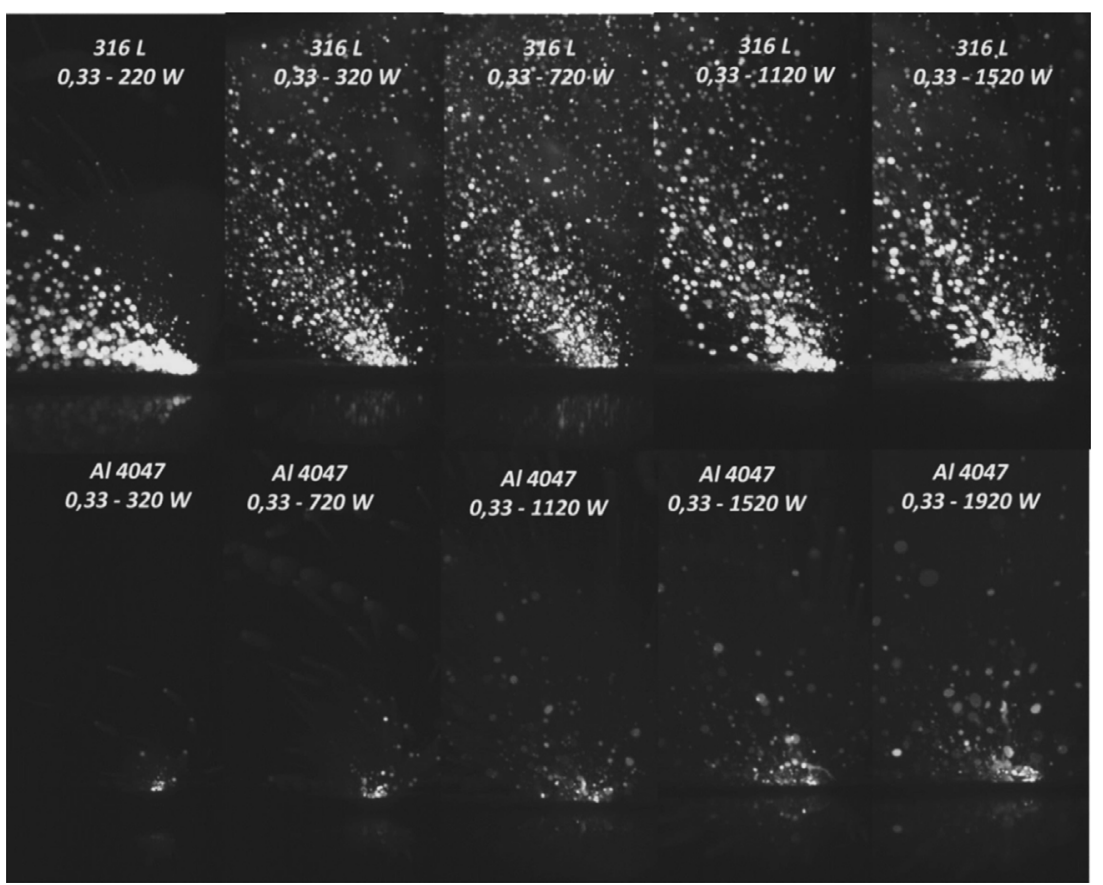

Fig. 8. superimposition of 1000 recorded images of spatters $\left(\mathrm{V}_{\mathrm{s}}=0.33 \mathrm{~m} / \mathrm{s}\right)$ for $316 \mathrm{~L}$ steel (upper) and A4047 (lower). From $220 \mathrm{~W}$ (left) to $1520 \mathrm{~W}$ (right) on $316 \mathrm{~L}$ and from $320 \mathrm{~W}$ (left) to $2320 \mathrm{~W}$ on A4047. 


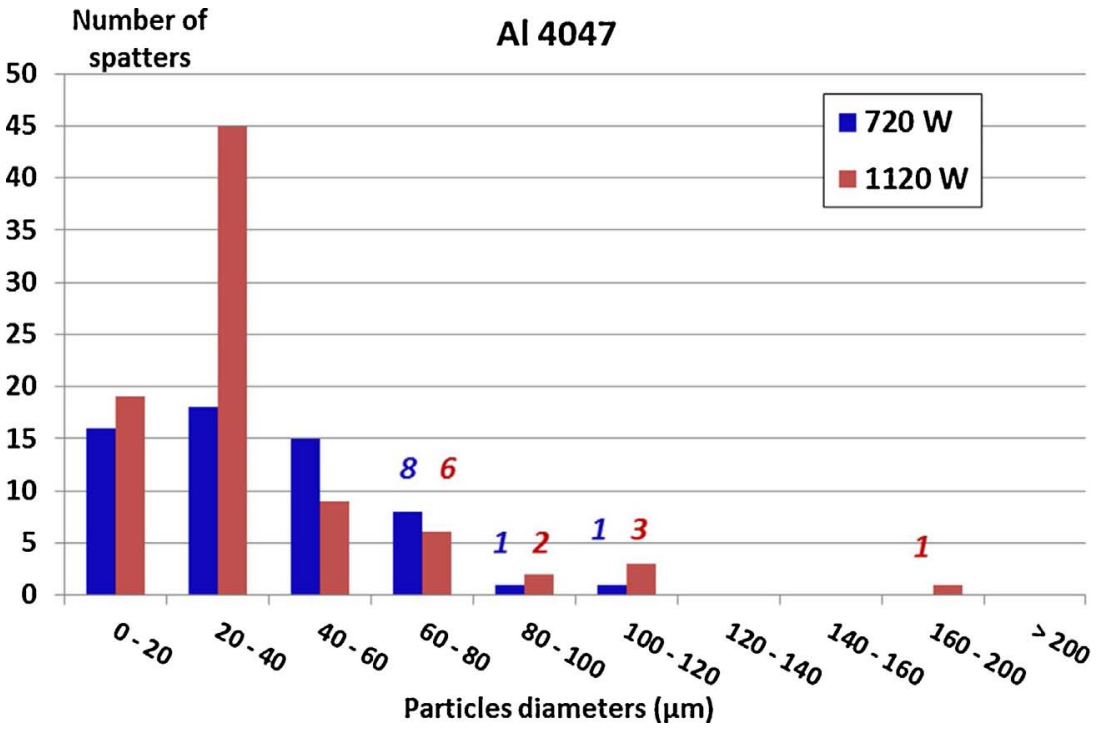

Fig. 9. Influence of process conditions on spatters generation on A4047 Aluminum alloy, $\mathrm{V}=0.33 \mathrm{~m} / \mathrm{s}, \mathrm{P}=720 \mathrm{~W}$ or $1220 \mathrm{~W}$. Compared with $316 \mathrm{~L}$ steel, a much lower amount of spatters is shown, and the influence of laser power is not obvious.
Number of spatters $>70 \mu \mathrm{m}$

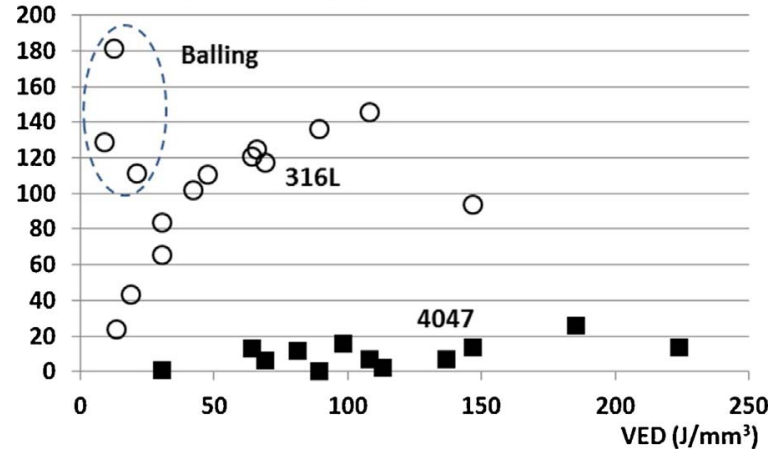

Fig. 10. Dependence of spatters versus volume energy density VED $\left(\mathrm{J} / \mathrm{mm}^{3}\right)$ on a $316 \mathrm{~L}$ powder bed.

initiated precisely at that location which combines a backwards metallic fluid acceleration with an upwards vapor column that shears the melt-pool edge (Fig. 15). Consequently, even in the early stages of keyhole formation (below $65 \mathrm{~J} / \mathrm{mm}^{3}$ ), the vaporization of melt-pool surface plays a dominant role on spatter formation.

Many publications since Kruth et al. (2004) have considered three main SLM regimes (balling, stable and balling) depending on $\mathrm{P} / \mathrm{V}$ ratio.
In the light of our recent work (Gunenthiram et al., 2016) and the present paper, we can first make a distinction between balling and humping as major unstable SLM regimes, and second correlate SLM regimes with spattering effect.

Therefore, four regimes can be assumed:

- An unstable (low VED, high velocity) regime where substrate is mostly un-melted. This results in the well-known balling effect where surface tensions act to sphéroïdise melt-pool. Spatters were found to be important in this regime.

- A first stable regime obtained for low VED values and moderate scanning velocities, which generates a conduction heating regime (with a limited vaporization, and low penetration depth d/ $\mathrm{D}<<1$ ) and a rather low amount of spatters

- A second stable regime obtained for moderate VED and moderate velocity values which operates under key-hole mode, and where melt-pool hydrodynamics are stable, generating rather deep penetration constant denudation and an increase of spatters formation with VED values. This regime is the most commonly used in SLM machines.

- An unstable "humping" mode for high VED values, severe vaporization (and large MP length-over-width ratios) combined with high velocities, where the melt-pool elongation tends to favor RayleighPlateau instabilities. As indicated by Fabbro (2010), this last regime

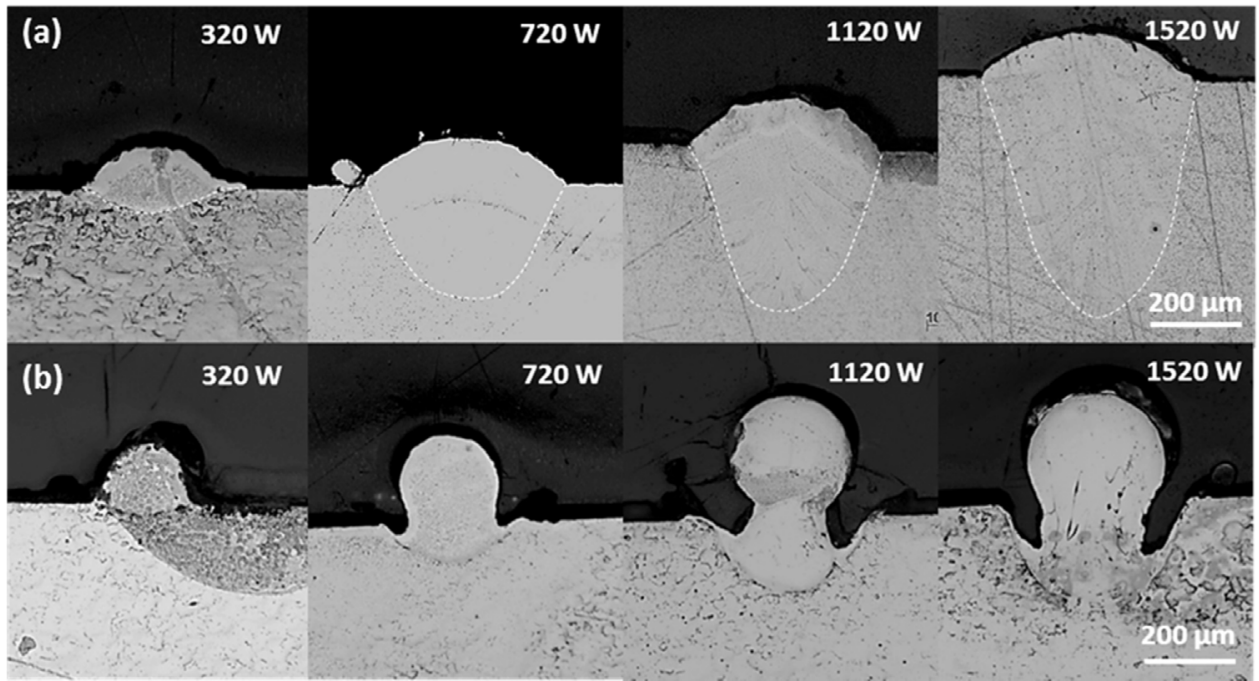

Fig. 11. Cross-sections of beads carried out on 316L with $\mathrm{D}=200 \mu \mathrm{m}$ spot diameter. (a) $\mathrm{V}=0.33 \mathrm{~m} / \mathrm{s}$ : the transition between a conduction regime and a key-hole regime large provoking aspect-ratio occurs between $320 \mathrm{~W}$ and $720 \mathrm{~W}$, (b) $\mathrm{V}=0.75 \mathrm{~m} / \mathrm{s}$ : above $320 \mathrm{~W}$, humping and undercuts are formed due to large length/width ratios that provoke hydrodynamic instability. 


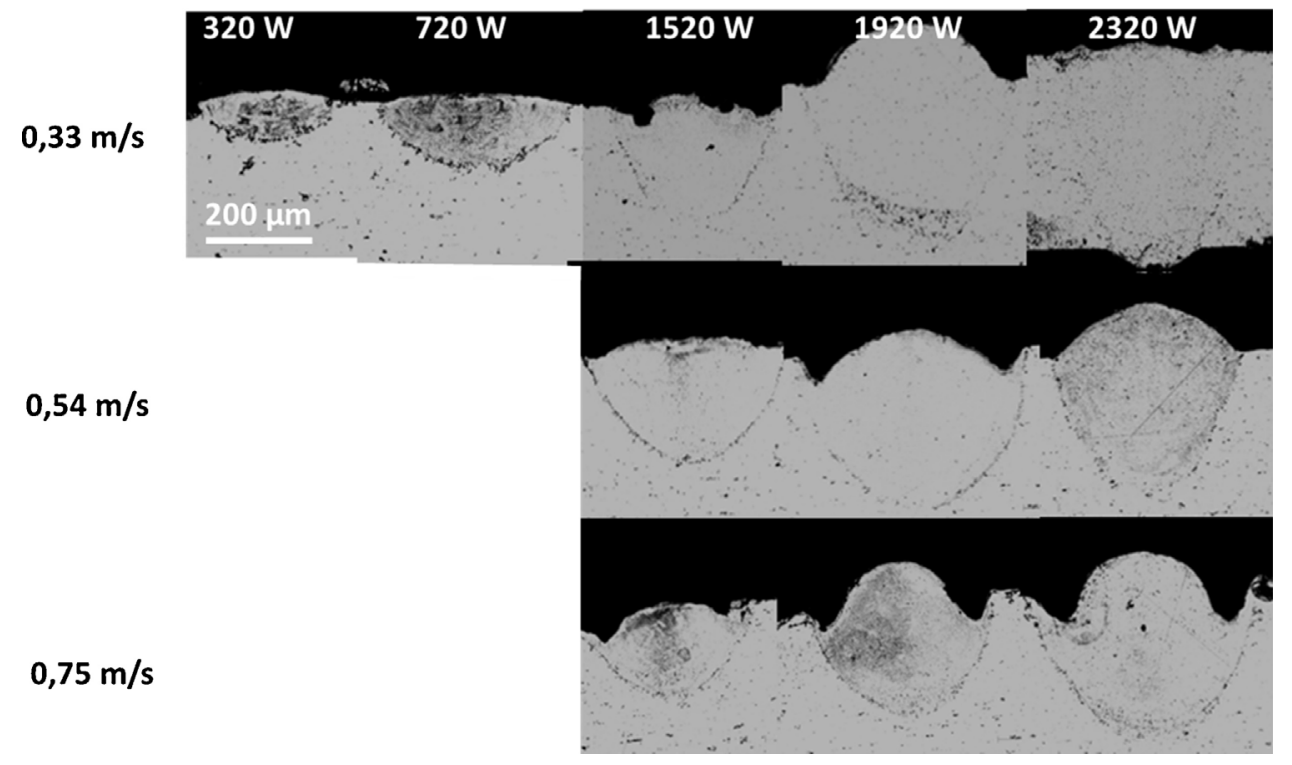

Fig. 12. Cross-sections of beads carried out on A4047 Al alloy with $\mathrm{D}=200 \mu \mathrm{m}$ spot diameter. for $\mathrm{V}_{\mathrm{s}}=0.33 \mathrm{~m} / \mathrm{s}, \quad \mathrm{V}_{\mathrm{s}}=0.54 \mathrm{~m} / \mathrm{s}$ and $\mathrm{V}_{\mathrm{s}}=0.75 \mathrm{~m} / \mathrm{s}$. Beads are unstable and begin to hump for $0.75 \mathrm{~m} / \mathrm{s}$ and $\mathrm{P}>1920 \mathrm{~W}$.

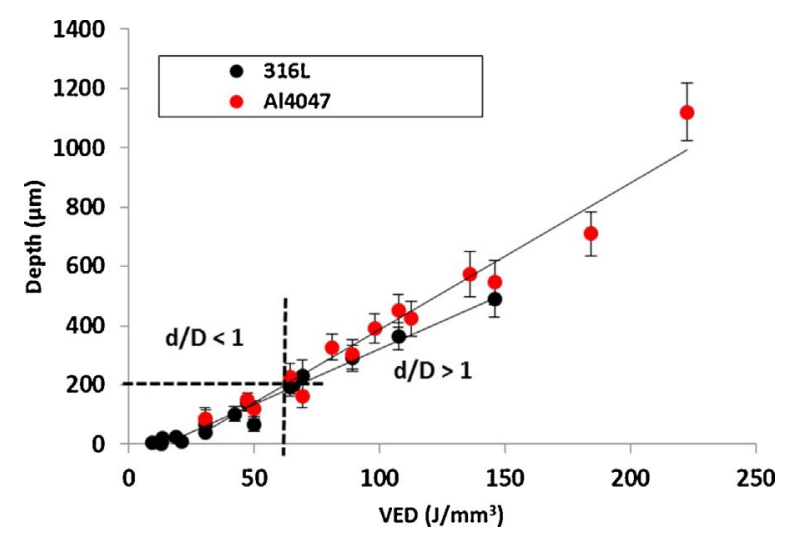

Fig. 13. Variation of bead depth $d$ with Volume energy density VED. A linear dependence is shown for both 316L and A4047. At a constant VED, higher d/D Ratios (between affected depth $\mathrm{d}$ and beam diameter D) are obtained on A4047 Al alloy than on 316L.

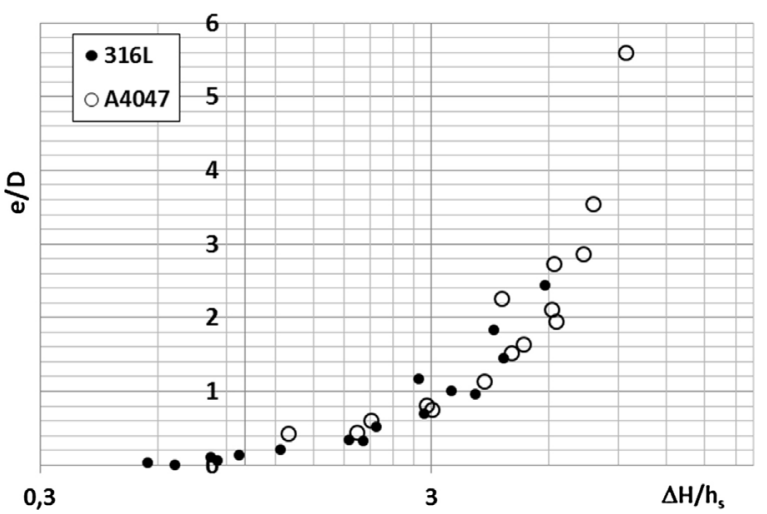

Fig. 14. Normalized bead penetration with versus normalized volume enthalpy $\Delta H / h_{s}$.

is a typical unstable welding regime where melt-pool is pushed upwards by fluid flow, and shrinked by surface tensions thus generating large undercuts.

For the last two conditions, all the physical phenomena involved (denudation, hydrodynamic instabilities, spatters) are assumed to be provoked by the MP vaporization, and the resulting key-hole formation.

An interesting aspect to address now is why spatters only initiate on a melt-pool surrounded by powder grains. Indeed, it was confirmed that no spattering phenomenon occurred for bead-on-plate trials at similar $\left(\mathrm{P}, \mathrm{V}_{\mathrm{s}}\right)$ conditions than those experienced on a $70 \mu \mathrm{m}$-thick powder bed. A possible explanation is that melt-pool is positioned below the powder bed surface due to the densification effect. Consequently, powder grains fall onto the melt-pool surface or are conduction-heated in the nearvicinity of the MP, coalesce instantaneously and can be either ejected (when vapor column is important enough) or incorporated in the MP.

It has to be mentioned here that the distinction between the different laser-melting regimes, and the corresponding VED values are mostly valid for single beads, representative of the first stages of a SLM process. Of course, the melt-pool instability and resulting spattering effect is also dependent on the number of SLM layers, and on the balance between input energy and heat dissipation, which is geometrydependent. This is expected to increase to some extent the amount of spatters. Such an influence could be addressed in a future work by imposing constant temperatures $\mathrm{T}_{0}$ (in-between $100{ }^{\circ} \mathrm{C}$ and $500{ }^{\circ} \mathrm{C}$ ) to the metallic substrate in order to check possible variations of spatters with $\mathrm{T}_{0}$.

\subsection{Influence of powder material and physical origin of spattering}

The reason why the powder bed material (stainless steel or aluminum alloy) affects the formation of spatters is not fully clear. Results clearly indicate a huge reduction of spatters on aluminum alloys (Figs. 8 and 10). Which necessitate further explanation. If we compare meltpool and surrounding powder bed behaviors, we can make the following observations:

- In both cases ( $\mathrm{Al}$ and steel) liquid droplets are formed in the near edge of the melt-pool, by conduction heating + capillarity followed by spheroïdization ( = local balling). At first sight, droplets are similar in shape and numbers. However, 316L droplets tend to be ejected when attracted by the upwards vapor plume whereas colder A4047 droplets (due to higher diffusivity $\alpha$ ) are directly incorporated in the melt-pool with a limited ejection.

- Velocities are nearly the same on Aluminum or steel spatters.

An estimation of spatter velocity was given by Matthews et al. (2016) (Eq. (3)), considering that the recoil pressure $\mathrm{P}(\mathrm{t})$ applied on the melt-pool directly drives fluid motion and resulting liquid droplets. However, considering our recent observations, most of the spatters are not initiated at the melt-pool surface thus contradicting some 
A- front view

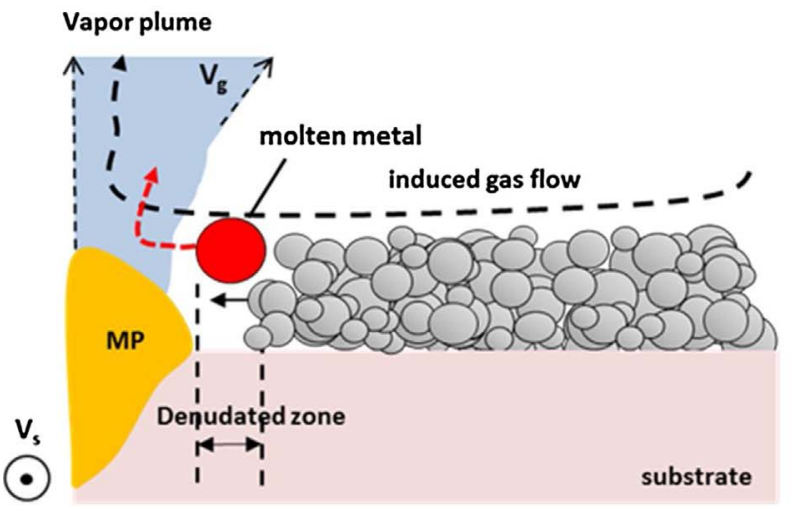

\section{B-Side view}

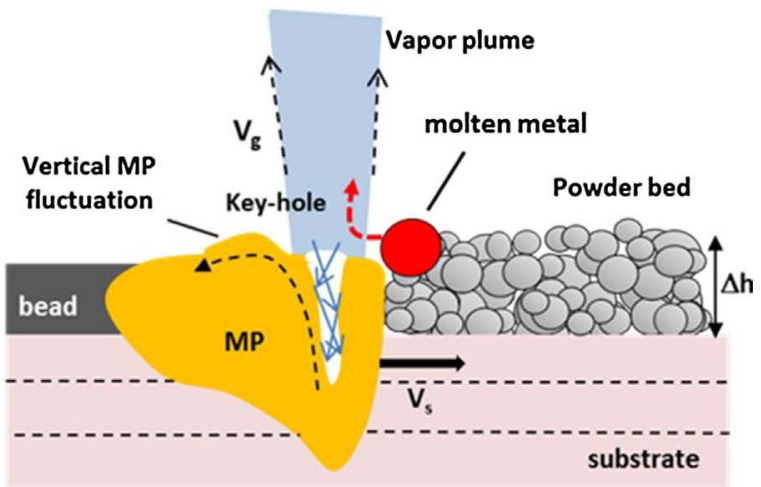

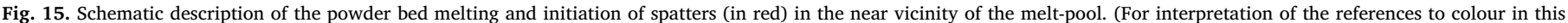
figure legend, the reader is referred to the web version of this article).

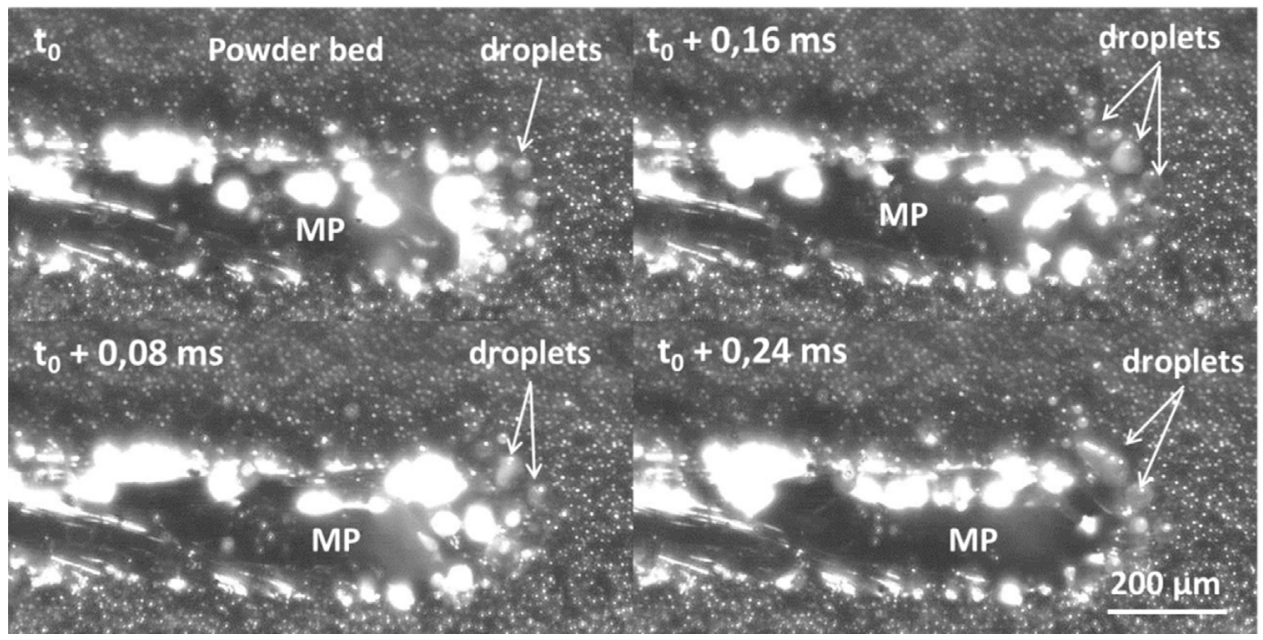

Fig. 16. Formation of droplets near the melt-pool front side during the selective laser melting of a 316L powder bed at low VED (P720V033 $\approx 11 \mathrm{~J} / \mathrm{mm}^{3}$ ) and large spot $(\approx 0.5 \mathrm{~mm}$, defocused $)=$ no key-hole is formed and no spattering occurs because droplets are directly incorporated to the MP.
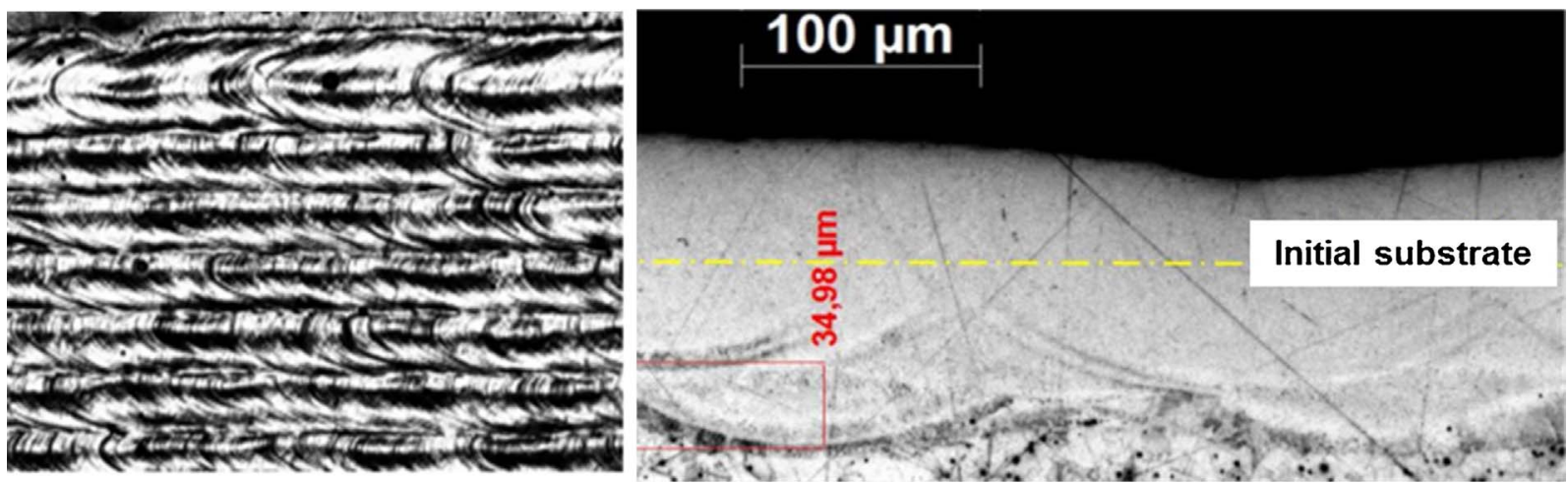

Fig. 17. Manufacturing of 3 SLM layers (powder thickness $=50 \mu \mathrm{m}$ ) using a D $=600 \mu \mathrm{m}$ top-hat laser irradiation (a) top surface of the 3rd layer, (b) cross-sectional analysis.

observations made by Wang et al. (2017), but near the melt-pool/ powder bed interface. Consequently, this "drilling velocity" directly cannot really be compared with our experimental data. This is confirmed by the fact that aluminum droplets reach similar velocities than steel ones, whereas they should reach higher ones when considering Eq. (3).

$\mathbf{U}=\sqrt{\frac{2 P}{\rho}}$

with $P(t)=P_{0} \exp \left(\Delta H \cdot\left(\frac{1}{T_{b}}-\frac{1}{T}\right)\right)$
Static irradiation tests on steel or aluminum power beds were also carried out with a large $0.5 \mathrm{~mm}$ spot to understand this difference of behavior. The difference is even more pronounced than in dynamic SLM melting mode: when the $316 \mathrm{~L}$ powder melts, balling $(100-500 \mu \mathrm{m})$ occurs but such small droplets tend to be ejected instantaneously whereas on A4047 powder, droplets tend to coalesce laterally to form a large molten sphere, without ejection.

From these data, an assumption can be made: due to the combination of a higher reflectivity and a 4-5 times higher thermal diffusivity of aluminum at the liquid state 316L (Table 1), the laser heat is instantaneously dissipated into the substrate. This limits temperature rise into aluminum droplets compared with steel ones. The resulting effect 
is a vaporization start on $316 \mathrm{~L}$ droplets which induces vapor pressure and puts them into motion at a $\mathrm{V}_{\mathrm{s}}$ velocity. Moreover, the vaporization enthalpy is nearly two times higher on aluminum alloys than on ironbased alloys (Table 1), which should limit vapor formation and resulting spatters on $\mathrm{Al}$ alloys.

Another assumption comes from the lower viscosity of aluminum melt-pool (Table 1) that could favor a direct incorporation of droplets into the melt-pool.

The suppression of spatters was shown to be possible by considering low VED values combined with larger spot diameters $(\mathrm{D} \approx 0.5-0.6 \mathrm{~mm}$ ). In this configuration (Fig. 16), a near-1D conduction regime is obtained but the molten depth (near $\mathrm{D} / 2$ ) is sufficient to provide enough dilution. Moreover, liquid droplets formed in the powder bed at the near-edge of the melt-pool are not ejected but directly incorporated in the melt-pool. Such a condition used in the hatching zones is expected to be beneficial for preserving the powder bed surface and improving the global quality of SLM parts. Similarly, an example of bead overlaps on 3 successive powder layers is presented in Fig. 17 for a top-hat $0.6 \mathrm{~mm}$ laser spot and confirms that the as-built material is dense, and that solidified beads (nearly $100 \mu \mathrm{m}$ in-depth) exhibit a top-surface stable geometry.

\section{Conclusions}

Metallic ejections generated during SLM were investigated using dedicated experimental tools including fast camera video recordings with variable orientation angles followed by image analysis. Increasing volumes of spatters were shown with the use of increasing volume energy densities (VED), and a correlation was proposed with melt-pool stability regimes. More spattering was shown on 316L stainless steel than on A4047 Aluminum alloy for similar SLM conditions.

The physical mechanism involved in the formation of spatters was systematically attributed to the vaporization phenomenon and the resulting vapor pressure occurring at the melt-pool surface, resulting in a near key-hole regime. Last, it was shown that a complete suppression of spatters was possible when using low volume energy densities combined with large spots to ensure sufficiently deep melt-pool penetrations.

\section{References}

Aboulkhair, N.T., Maskery, I., Tick, C., Ashcroft, I., Everitt, N.M., 2016. On the formation of AlSi10Mg single tracks and layers in selective laser melting: microstructure and nano-mechanical properties. J. Mater. Process. Technol. 230, 88-98.

Fabbro, R., 2010. Melt pool and keyhole behaviour analysis for deep penetration lase welding. J. Phys. D: Appl. Phys. 43, 445-501.

Gu, D., Shen, Y., 2009. Balling phenomena in direct laser sintering of stainless steel powder: metallurgical mechanisms and control methods. Mater. Des. 30, 2903-2910.

Gunenthiram, V., Peyre, P., Schneider, M., Dal, M., Coste, F., Fabbro, R., 2016. Analysis of laser-melt-pool-powder bed interaction during the selective laser melting of a stainless steel. In: Proceedings of ICALEO'16. San Diego, USA, October 19-23.

Hann, D.B., Iammi, J., Folkes, J., 2011. A simple methodology for predicting laser-weld properties from material and laser parameters. J. Phys. D: Appl. Phys. 44, 445401.

Khairallah, S.A. Anderson, A.T., 2014. Mesoscopic simulation model of selective laser melting of stainless steel powder. J. Mater. Process. Technol. 214, 2627-2636.

Khairallah, S.A., Anderson, A.T., Rubenchik, A., King, W.E., 2016. Laser-powder bed fusion additive manufacturing: physics if complex melt flow and formation mechanisms of pores, spatter and denudation zones. Acta Mater. 108, 36-45.

King, W.E., Barth, H.D., Castillo, V.M., Gallegos, G.F., Gibbs, J.W., Hahn, D.E., Kamath, C., Rubenchik, A.M., 2014. Observation of key-hole mode laser melting in laser powder bed fusion additive manufacturing. J. Mater. Process. Technol. 214 2915-2925.

Kruth, J.P., Froyen, L., Van Vaerenbergh, J., Mercelis, P., Rombouts, M., Lauwers, B., 2004. Selective laser melting of iron-based powder. J. Mater. Process. Technol. 149, 616-622.

Liu, Y., Yang, Y., Mai, S., Wang, D., Song, C., 2015. Investigation into spatter behavior during selective laser melting of AISI 316L stainless steel powder. Mater. Des. 87, 797-806.

Masmoudi, A., Bolot, R., Coddet, C., 2015. Investigation on the laser-powder-atmosphere interaction zone during selective laser-melting. J. Mater. Process. Technol. 225, $122-132$.

Matthews, M.J., Guss, G., Khairallah, S.A., Rubenchik, A.M., Depond, P.J., King, W.E., 2016. Denudation of metal powder layers in laser powder bed fusion processes. Acta Mater. 114, 33-42.

Mills, K.C., 2002. In: ASM International (Ed.), Recommended Values of Thermo-Physical Properties for Selected Commercial Alloys. Woodhead Publishing.

Ozel, T., Arisoy, Y.M., Criales, L.E., 2016. Computational simulation of thermal and spattering phenomena and microstructure in selective laser melting of inconel 625 . Phys. Procedia 83, 1435-1443.

Qiu, C., Panwisawas, C., Ward, M., Basoalto, H.C., Brooks, J.W., Attalah, M.M., 2015. On the role of melt-pool flow into the surface structure and porosity development during selective laser melting. Acta Mater. 96, 72-79.

Scipioni Bertoli, U., Wolfer, A.J., Matthews, M.J., Delplanque, J.P., Schoenung, J.M., 2017. On the limitation of volumetric energy density as a design parameter for selective laser melting. Mater. Des. 113, 331-340.

Simonelli, M., Tuck, C., Aboulkhair, N.T., Maskery, I., Ashcroft, I., Wildman, R.D., Hague, R., 2015. A study on the Laser Spatter and the oxidation reactions during selective laser melting of 316L stainless steel, Al-10Si6Mg and Ti-6Al-4V. Metall. Mater. Trans. A 46A, 3842.

Wang, D., Wu, S., Fu, F., Mai, S., Yang, Y., Liu, Y., Song, C., 2017. Mechanisms and characteristics of spatter generation in SLM processing and its effect on the properties. Mater. Des. 117, 121-130.

Wu, D., Hua, X., Ye, D., Li, F., 2017. Understanding of humping formation and suppression mechanisms using the numerical simulation. Int. J. Heat Mass Transfer 104, 634-643.

Yadroitsev, I., Gusarov, A., Yadroitseva, I., Smurov, I., 2010. Single track formation in selective laser melting of metal powders. J. Mater. Process. Technol. 210, 1624-1631.

Zhou, X., Liu, X., Zhang, D., Shen, D., Liu, W., 2015. Balling phenomena in selective laser melted tungsten. Acta Mater. 98, 1-16. 